07;09

\title{
Особенности вольт-амперной характеристики микродисковых лазеров на основе квантовых ям-точек InGaAs/GaAs
}

\author{
() Ф.И. Зубов ${ }^{1}$, Э.И. Моисеев ${ }^{1}$, Г.О. Корнышов ${ }^{1}$, Н.В. Крыжановская ${ }^{1}$, Ю.М. Шерняков ${ }^{2}$, А.С. Паюсов ${ }^{2}$, \\ М.М. Кулагина ${ }^{2}$, Н.А. Калюжный ${ }^{2}$, С.А. Минтаиров ${ }^{2}$, М.В. Максимов ${ }^{1}$, А.Е. Жуков ${ }^{1, \text { ฯ }}$ \\ ${ }^{1}$ Санкт-Петербургский национальный исследовательский Академический университет РАН, Санкт-Петербург, Россия \\ ${ }^{2}$ Физико-технический институт им. А.Ф. Иофффе РАН, Санкт-Петербург, Россия \\ I E-mail: zhukale@gmail.com
}

Поступило в Редакцию 19 июня 2019г.

В окончательной редакции 19 июня 2019г.

Принято к публикации 20 июня 2019 г.

\begin{abstract}
Исследованы сформированные глубоким травлением инжекционные микролазеры с активной областью на основе массивов квантовых ям-точек InGaAs/GaAs. Характер изменения вольт-амперной характеристики при уменьшении диаметра микролазеров указывает на формирование непроводящего электрический ток слоя толщиной около $1.5 \mu \mathrm{m}$ вблизи боковой поверхности, что приводит к уменьшению эффективной площади протекания тока.
\end{abstract}

Ключевые слова: полупроводниковый лазер, микролазер, квантовые точки, вольт-амперная характеристика.

DOI: 10.21883/PJTF.2019.19.48316.17938

Микродисковые лазеры $[1,2]$ активно исследуются в последние годы в связи с перспективами их использования в качестве компактных источников для систем оптической связи на кристалле. Оптический резонатор таких лазеров формируется с помощью глубокого травления эпитаксиальной гетероструктуры сквозь волновод и активную область. В связи с этим на характеристики микролазеров заметное влияние может оказывать безызлучательная (поверхностная) рекомбинация на боковых стенках микрорезонатора [3], в особенности при использовании упрощенной технологии изготовления без пассивации стенок. Однако в случае микродисковых лазеров с активной областью, представляющей собой массив самоорганизующихся квантовых точек (КТ), влияние безызлучательной рекомбинации оказывается не столь значительным. В пользу этого свидетельствуют низкие пороговые плотности тока $\left(250 \mathrm{~A} / \mathrm{cm}^{2}[4]\right)$ и высокая предельная температура генерации $\left(100^{\circ} \mathrm{C}[5]\right)$. Считается, что нечувствительность микролазеров на основе КТ к поверхностной рекомбинации обусловлена подавлением латерального транспорта носителей заряда в плоскости КТ [6].

Недавно в качестве активной области микродисковых лазеров было предложено использовать так называемые квантовые ямы-точки (КЯТ), представляющие собой плотный массив In-обогащенных островков, формируемых методом газофазной эпитаксии из металлоорганических соединений (МОГФЭ) слоя InGaAs на слаборазориентированную поверхность GaAs [7]. Высокие рабочая температура, коэффициент полезного действия, выходная мощность, а также частоты модуляции свыше $6 \mathrm{GHz}$ [8], достигнутые в микродисковых лазерах на основе КЯТ, свидетельствуют о перспективности исполь- зования этого типа наноструктур. В то же время многие их характеристики изучены не в полной мере.

В настоящей работе нами исследованы вольтамперные характеристики (BAX) микролазеров с активной областью на основе КЯТ. Полученные результаты позволяют сделать вывод о подавлении протекания тока в области вблизи боковых стенок.

Для изготовления микролазеров была использована гетероструктура, синтезированная методом МОГФЭ на подложке $n^{+}$-GaAs, разориентированной на $6^{\circ}$ относительно плоскости (100). Активная область представляла собой пять слоев КЯТ $\mathrm{In}_{0.4} \mathrm{Ga}_{0.6} \mathrm{As}$, помещенных в середину волновода GaAs толщиной $0.79 \mu \mathrm{m}$, ограниченного эмиттерными слоями $\mathrm{AlGaAs} n$ - и $p$-типа проводимости. Микродисковые резонаторы диаметром $D$ от 10.5 до $31 \mu \mathrm{m}$ формировались глубоким плазмохимическим травлением сквозь волновод. Микролазеры имели общий $n$-контакт $\mathrm{AuGe} / \mathrm{Ni} / \mathrm{Au}$, размещенный на тыльной стороне подложки. Индивидуальные $p$-контакты $\mathrm{AgMn} / \mathrm{NiAu}$ были расположены на вершинах микродисков и имели диаметр, примерно на $3 \mu \mathrm{m}$ меньший, чем диаметр самого диска (вставка на рис. 1). Микродиски были затем планаризованы с помощью резиста SU-8. Измерения проводились без температурной стабилизации.

При большом прямом смещении и высоких плотностях тока, характерных для рабочих режимов инжекционных лазеров, напряжение $U$ упрощенно описывается линейной функцией тока $I$ [9]: $U \approx U_{0}+I R_{S}$, где $U_{0}$ - напряжение открывания $p-n$-перехода, $R_{S}$ последовательное сопротивление, связанное с протеканием тока через последовательность слоев, образующих лазерную структуру, а также с сопротивлением контактов. Если протекание тока ограничено в пределах активной области площади $S_{a c t}$, ВАХ может быть за- 


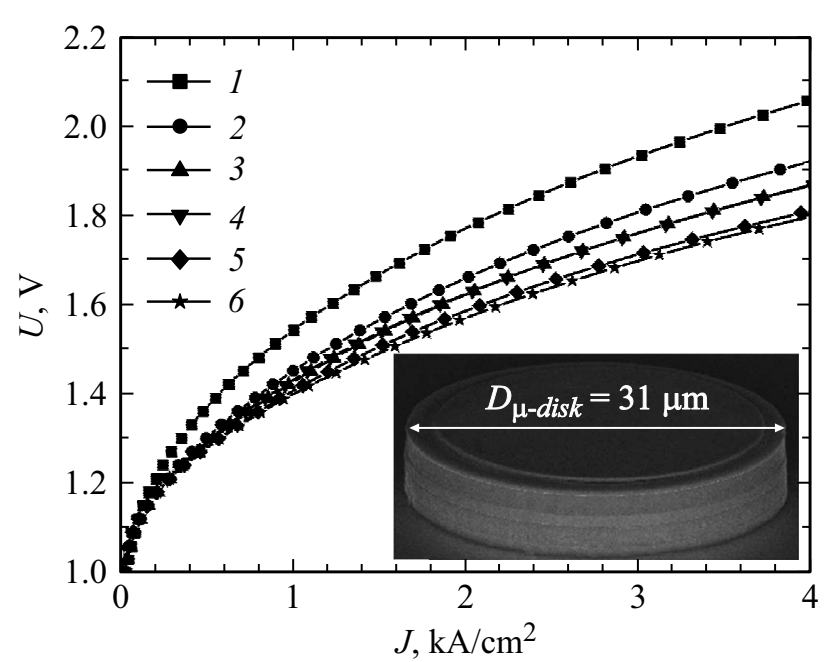

Рис. 1. Зависимость напряжения на диоде $U$ от плотности тока $J$ (ток инжекции, отнесенный к площади мезы травления) для микролазеров разного диаметра. $D, \mu \mathrm{m}: 1-10.5,2-14.5$, $3-19,4-23,5-27,6-31$. На вставке - изображение микродиска диаметром $31 \mu \mathrm{m}$ со сформированным верхним контактом до планаризации.

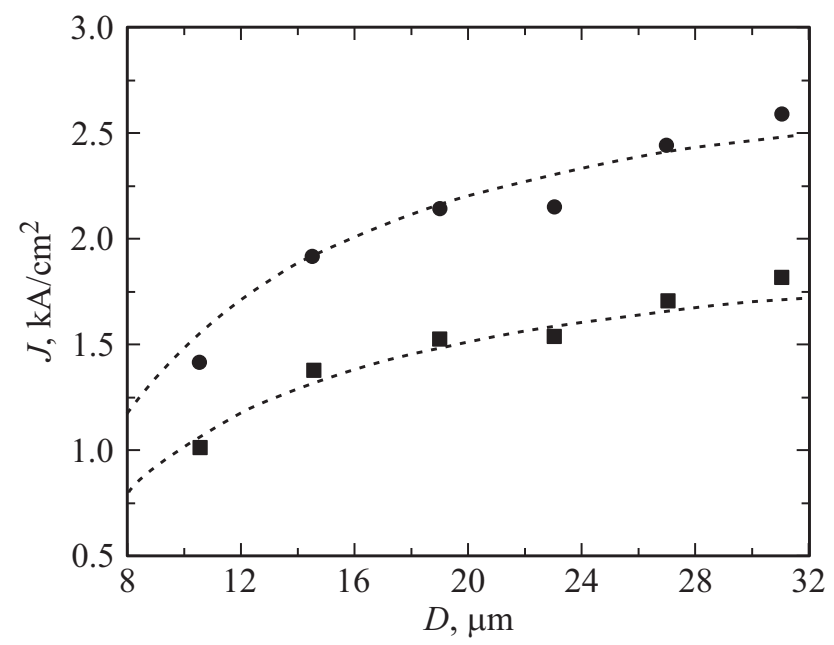

Рис. 2. Зависимость плотности тока $J$, соответствующей фиксированному напряжению $U=1.55 \mathrm{~V}$ (квадраты) или $1.65 \mathrm{~V}$ (кружки), от диаметра микродиска. Штриховые линии аппроксимация выражением (1).

писана в терминах плотности тока инжекции $J=I / S_{a c t}$ как $U \approx U_{0}+J \rho_{S}$, где $\rho_{S}$ представляет собой удельное последовательное сопротивление $\left(R_{S}=\rho_{S} / S_{a c t}\right)$. Таким образом, для лазерных диодов с различной площадью активной области ВАХ в такой записи должна оставаться неизменной.

В случае микродисковых лазеров под площадью активной области обычно понимается площадь сечения мезы $\pi D^{2} / 4$. На рис. 1 показаны ВАХ нескольких микродисковых лазеров разного диаметра, для которых плотность тока вычислена указанным выше способом, т. е. $J=I /\left[\pi D^{2} / 4\right]$. Как видно, ВАХ существенно разли- чаются, причем при фиксированном напряжении диоды меньшего размера характеризуются и меньшей плотностью тока $J$. Такое поведение может быть объяснено, если предположить, что реальный размер $D_{\text {eff }}$ области протекания тока в микродисковых лазерах на некоторую величину $\delta$ меньше геометрического размера их сечения: $D_{e f f}=D-\delta$. Тогда истинная плотность тока будет равна $J_{\text {eff }}=I /\left[\pi D_{\text {eff }}^{2} / 4\right]$, т. е. окажется в $D^{2} /(D-\delta)^{2}$ раз больше, чем плотность тока $J$, вычисленная в предположении протекания тока по всей площади сечения мезы.

Для определения величины $\delta$ мы проанализировали экспериментальную зависимость плотности тока $J$ при фиксированном напряжении $U$ от диаметра микродиска. На рис. 2 приведен пример для случаев $U=1.55$ и 1.65 V. Выражение

$$
J=D^{2} /(D-\delta)^{2} J_{e f f}
$$

удовлетворительно описывает экспериментальные данные и позволяет определить истинную плотность тока $J_{e f f}$, соответствующую выбранному напряжению (2.1 и $3.1 \mathrm{kA} / \mathrm{cm}^{2}$ для $U$, показанных на рис. 2), а также общее для всех $U$ значение $\delta$. Последнее оказалось равным $3 \mu \mathrm{m}$.

На рис. 3 приведены ВАХ для микролазеров различного диаметра, для построения которых плотность тока инжекции вычислялась в предположении, что размер области протекания тока для всех микродисков меньше геометрического размера сечения на $3 \mu \mathrm{m}$. Как видно, BAX для всех диодов в таком представлении хорошо согласуются друг с другом. Это означает, что вблизи боковых стенок исследуемых микролазеров имеется область шириной $\delta / 2=1.5 \mu \mathrm{m}$, ток инжекции через которую не протекает.

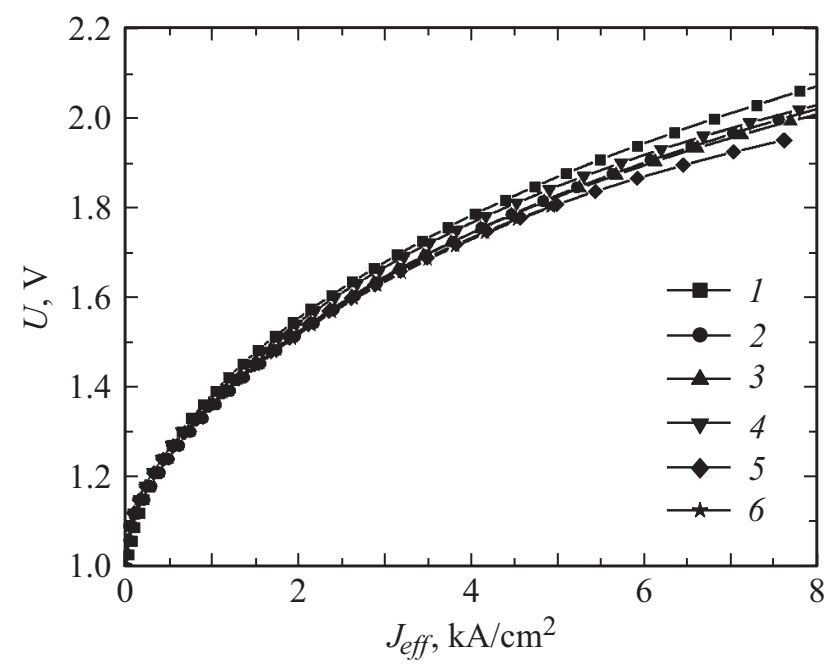

Рис. 3. Зависимость напряжения на диоде $U$ от эффективной плотности тока $J_{e f f}$, вычисленной в предположении, что диаметр области протекания тока меньше диаметра мезы на $3 \mu \mathrm{m}$, для микролазеров разного диаметра $D$ (обозначения те же, что на рис. 1). 
Подобное явление имеет место, например, в лазерах с оксидной апертурой, где площадь активной области задается не размером мезы, а размером области, оставшейся неокисленной. Однако в исследуемых в настоящей работе микролазерах отсутствуют слои с высоким содержанием алюминия (мольная доля $\mathrm{Al}$ в эмиттерных слоях составляет менее 40\%), которые могли бы подвергнуться непреднамеренному окислению. Скорее всего, причина кроется в формировании у боковых стенок поврежденного непроводящего слоя. Однако то обстоятельство, что диаметр области протекания тока фактически совпадает с диаметром верхнего электрического контакта, позволяет для объяснения особенностей BAX предположить отсутствие латерального растекания носителей заряда.

Таким образом, нами исследованы микродисковые лазеры диаметром от 10.5 до $31 \mu \mathrm{m} \mathrm{c}$ активной областью, представляющей собой массив квантовых ямточек InGaAs. Показано, что для корректного сравнения BAX микролазеров различного диаметра значение плотности тока следует вычислять, полагая площадь протекания тока меньше на $3 \mu \mathrm{m}$, чем диаметр сечения глубокой мезы.

\section{Финансирование работы}

Работа выполнена при поддержке Российского фонда фундаментальных исследований (16-29-03127-ОФИ-М) и Минобрнауки РФ (3.9787.2017/8.9).

\section{Конфликт интересов}

Авторы заявляют, что у них нет конфликта интересов.

\section{Список литературы}

[1] Munsch M., Claudon J., Malik N.S., Gilbert K., Grosse P., Gerard J.-M., Albert F., Langer F., Schlereth T., Pieczarka M.M., Hofling S., Kamp M., Forchel A., Reitzenstein S. // Appl. Phys. Lett. 2012. V. 100. N 3. P. 031111.

[2] Zou L.-X., Huang Y.-Zh., Liu B.-W., Lv X.-M., Ma X.-W., Yang Y.-D., Xiao J.-L., Du Y. // Opt. Express. 2015. V. 23. N 3. P. $2879-2888$.

[3] Coldren L.A., Corzine S.W., Masanovic M.L. Diode lasers and photonic integrated circuit. 2nd ed. Hoboken, N.J., USA: Wiley, 2012. Section 4.5.2.

[4] Moiseev E.I., Kryzhanovskaya N.V., Zubov F.I., Mikhailovskii M.S., Abramov A.N., Maximov M.V., Kulagina M.M., Guseva Yu.A., Livshits D.A., Zhukov A.E. // Semiconductors. 2019. In press.

[5] Kryzhanovskaya N.V., Moiseev E.I., Kudashova Yu.V., Zubov F.I., Lipovskii A.A., Kulagina M.M., Troshkov S.I., Zadiranov Yu.M., Livshits D.A., Maximov M.V., Zhukov A.E. // Electron. Lett. 2015. V. 51. N 17. P. 1354-1355.

[6] Ouyang D., Ledentsov N.N., Bimberg D., Kovsh A.R., Zhukov A.E., Mikhrin S.S., Ustinov V.M. // Semicond. Sci. Technol. 2003. V. 18. N 12. P. L53-L54.
[7] Moiseev E., Kryzhanovskaya N., Maximov M., Zubov F., Nadtochiy A., Kulagina M., Zadiranov Yu., Kalyuzhnyy N., Mintairov S., Zhukov A. // Opt. Lett. 2018. V. 43. N 19. P. 4554-4557.

[8] Kryzhanovskaya N.V., Moiseev E.I., Zubov F.I., Mozharov A.M., Maximov M.V., Kalyuzhnyy N.A., Mintairov S.A., Kulagina M.M., Blokhin S.A., Kudryavtsev K.E., Yablonskiy A.N., Morozov S.V., Berdnikov Yu., Rouvimov S., Zhukov A.E. // Photon. Res. 2019. V. 7. N 6. P. 664-668.

[9] Bour D.P., Rosen A. // J. Appl. Phys. 1989. V. 66. N 7. P. $2813-$ 2818. 